\title{
Blood pressure-lowering effects of beetroot juice and novel beetroot- enriched bread products in normotensive male subjects
}

\author{
Ditte A. Hobbs ${ }^{1,2}$, Nedi Kaffa ${ }^{1,2}$, Trevor W. George ${ }^{3}$, Lisa Methven ${ }^{1}$ and Julie A. Lovegrove ${ }^{1,2 *}$ \\ ${ }^{1}$ Hugh Sinclair Unit of Human Nutrition, Department of Food and Nutritional Sciences, School of Chemistry, Food and \\ Pharmacy, The University of Reading, Whiteknights, PO Box 226, Reading, Berks RG6 6AP, UK \\ ${ }^{2}$ Institute for Cardiovascular and Metabolic Research (ICMR), University of Reading, Whiteknights, PO Box 226, Reading, \\ Berks RG6 6AP, UK \\ ${ }^{3}$ Eccentricities Limited, Frimley Green Road, Frimley Green, Camberley, Surrey GU16 6NA, UK
}

(Submitted 11 October 2011 - Final revision received 4 January 2012 - Accepted 11 January 2012 - First published online 14 March 2012)

\section{Abstract}

A number of vegetables have a high nitrate content which after ingestion can be reduced to nitrite by oral bacteria, and further to vasoprotective NO endogenously. In the present study, two separate randomly controlled, single-blind, cross-over, postprandial studies were performed in normotensive volunteers. Ambulatory blood pressure (BP) was measured over a $24 \mathrm{~h}$ period following consumption of either four doses of beetroot juice (BJ), 0, 100, 250 and $500 \mathrm{~g}(n$ 18), or three bread products, control bread ( $0 \mathrm{~g}$ beetroot), red beetroot- and white beetroot-enriched breads ( $n$ 14). Total urinary nitrate/nitrite $\left(\mathrm{NO}_{x}\right)$ was measured at baseline, and at 2,4 and $24 \mathrm{~h}$ post-ingestion. $\mathrm{BJ}$ consumption significantly, and in a near dose-dependent manner, lowered systolic BP (SBP, $P<0 \cdot 01)$ and diastolic BP (DBP, $P<0 \cdot 001)$ over a period of $24 \mathrm{~h}$, compared with water control. Furthermore, bread products enriched with $100 \mathrm{~g}$ red or white beetroot lowered SBP and DBP over a period of $24 \mathrm{~h}$ (red beetroot-enriched bread, $P<0.05$ ), with no statistical differences between the varieties. Total urinary $\mathrm{NO}_{x}$ significantly increased following the consumption of $100 \mathrm{~g}(P<0 \cdot 01), 250 \mathrm{~g}(P<0 \cdot 001)$ and $500 \mathrm{~g}$ BJ $(P<0 \cdot 001)$ and after red beetrootenriched bread ingestion $(P<0.05)$, but did not reach significance for white beetroot-enriched bread compared with the no-beetroot condition. These studies demonstrated significant hypotensive effects of a low dose $(100 \mathrm{~g})$ of beetroot which was unaffected by processing or the presence of betacyanins. These data strengthen the evidence for cardioprotective BP-lowering effects of dietary nitrate-rich vegetables.

Key words: Beetroot: Blood pressure: Nitrate: Nitrite: Nitric oxide

High blood pressure (BP) or hypertension (BP of $>140$ / $90 \mathrm{mmHg}$ ) is a major public health burden. Worldwide, in 2001, 13.5\% of all premature deaths were attributed to high $\mathrm{BP}^{(1)}$. Moreover, hypertension is a major risk factor for the progression of $\mathrm{CVD}^{(2-4)}$, the leading cause of death in England. Individuals with uncontrolled hypertension are at an almost 3-fold higher risk of developing CVD compared with normotensive individuals ${ }^{(5)}$. Evidence suggests that a reduction in mean diastolic BP (DBP) by $5-6 \mathrm{mmHg}$ over 5 years would decrease the incidence of stroke and $\mathrm{CHD}^{(6)}$. Recent reports have suggested that the treatment of hypertension should occur before the disease evolves, in patients with prehypertension or in normotensives ${ }^{(7)}$. Therefore, novel cost-effective strategies are needed for the treatment of this condition.

Increased fruit and vegetable consumption protects against CVD and hypertension ${ }^{(8,9)}$. These cardioprotective effects have previously been attributed to several different nutrients found in vegetables such as antioxidant vitamins and flavonoids. However, clinical trials fail to ascertain the beneficial effects $^{(10,11)}$. Although the health benefits from a diet rich in fruits and vegetables are likely to be multi-factorial, epidemiological studies have shown specific food groups such as green leafy vegetables to have the greatest protection against CHD and ischaemic stroke risk $^{(12,13)}$. Along with beetroot (Beta vulgaris), these are among the highest nitrate-accumulating vegetables.

The continuous production of NO by the endothelium plays an important role in the maintenance of vascular homeostasis. Hypertension and other risk factors for CVD may be partly associated with a diminished release of $\mathrm{NO}$ into the arterial wall ${ }^{(14)}$, due to inefficient synthesis or increased oxidative destruction. Increasing evidence suggests that NO can be biosynthesised in vivo following ingestion of inorganic nitrate ${ }^{(15)}$ or dietary nitrate from beetroot juice $(\mathrm{BJ})^{(16)}$, by a process that

Abbreviations: ABP, ambulatory blood pressure; BJ, beetroot juice; BP, blood pressure; DBP, diastolic blood pressure; NO , nitrate/nitrite; SBP, systolic blood pressure.

*Corresponding author: Professor J. A. Lovegrove, email j.a.lovegrove@reading.ac.uk 
is independent of the conventional L-arginine NO synthase pathway. The activity of ingested nitrate relies on its conversion to nitrite by commensal Gram-negative bacteria residing in the oral cavity and enters the circulation after absorption in the stomach. In the blood vessel wall ${ }^{(17)}$ and erythrocytes $^{(18)}$, the nitrite is reduced to NO and other nitrogen oxides, ultimately leading to vasodilation, $\mathrm{BP}$ maintenance and protection against ischaemia-reperfusion injury ${ }^{(19)}$. Ingestion of $500 \mathrm{ml} \mathrm{BJ}$ by normotensives has been shown to reduce $\mathrm{BP}$, inhibit platelet aggregation and prevent endothelial dysfunction induced by an acute ischaemic insult to the forearm $^{(16)}$.

In addition, beetroot is particularly rich in betalains, a group of nitrogen-containing colour compounds that are not commonly represented among edible plants. Betalains can be divided into two subclasses: the red/purple betacyanins which are responsible for the colour of red beetroot or the yellow/orange betaxanthins that contribute to the colour of yellow beetroot. White beetroot is deficient in betacyanins, but no other differences between beetroot varieties have been reported in the literature. Betalains have been shown to act as antioxidants, by the donation of electrons ${ }^{(21,22)}$, and inhibit lipid peroxidation and haem decomposition in vitro ${ }^{(23)}$, suggesting a role of these compounds in protection against certain oxidative stress-related diseases, such as hypertension and CVD.

In the present study, two novel studies were performed. The aim of study 1 was to determine the dose-dependent effect of nitrate-rich $\mathrm{BJ}$ on $24 \mathrm{~h}$ ambulatory $\mathrm{BP}$ (ABP) to establish the lowest dose of nitrate contained within $\mathrm{BJ}$ to have a functional effect on BP. Bread is a versatile and widely consumed food and may be an effective vehicle to increase vegetable consumption without significant dietary changes. Study 2 was performed to determine whether beetrootenriched bread had similar beneficial effects on BP as BJ, and as a secondary objective to assess the impact of betalains on $\mathrm{BP}$ reduction.

\section{Methods and procedure}

\section{Subjects}

The study was conducted according to the guidelines laid down in the Declaration of Helsinki and all procedures involving human subjects were approved by the University of Reading Research Ethics Committee (approval no.: study 1, 09/25; study 2, 09/48). All subjects gave their written informed consent. Separate recruitment was carried out for each of the studies. The subjects were recruited from the University of Reading and the surrounding Reading areas by email, posters and Internet advertisements. Potential subjects attended a screening visit following a $12 \mathrm{~h}$ fast. BP and anthropometric measurements were taken followed by two blood samples, one of which was sent to the local hospital (Royal Berkshire Hospital) for full blood count analysis and the second for in-house analysis of fasting blood lipids, glucose, liver and kidney function using the ILAB 600 (Instrumentation Laboratories Limited). Subjects were selected if they met the study criteria of the following: no known liver disease, diabetes mellitus or a diagnosed mycocardial infarction; no gall bladder problems or abnormalities of fat metabolism; no subjects on weight-reducing diets or taking medication likely to affect $\mathrm{BP}$; no vigorous exercise $(>3$ times/week, $<20 \mathrm{~min}$ each session) or excess consumption of alcohol ( $>150 \mathrm{ml} /$ week); $\mathrm{BMI}<30 \mathrm{~kg} / \mathrm{m}^{2} ; \mathrm{BP}<150 / 90 \mathrm{mmHg}$ and $\mathrm{Hb}$ in the range of $138-182 \mathrm{~g} / \mathrm{l}$. None of the subjects smoked or had a history of recent serious acute or chronic illness.

\section{Experimental design}

Subjects were recruited to take part in two separate randomised, controlled, single-blind, cross-over, test meal studies conducted at the Hugh Sinclair Unit of Human Nutrition at the University of Reading, during two separate periods from June to September 2008 and June to November 2009. There were at least $7 \mathrm{~d}$ washout period between each study day. All subjects were asked to refrain from consuming alcohol and caffeine or undertake any strenuous physical activity for $24 \mathrm{~h}$ before each intervention day and were provided with a standard evening meal supplied before each visit. On each study day, subjects arrived at 08.00 hours at the Hugh Sinclair Unit of Human Nutrition at the University of Reading after a $12 \mathrm{~h}$ fast. After a baseline urine sample, subjects were fitted with an ABP monitor and four baseline measurements were taken.

Study 1. The first study investigated the dose-dependent effects of BJ in eighteen healthy normotensive males. They were randomised to receive one of four different intervention drinks: $0 \mathrm{~g}$ BJ (500g water) as a control; $100 \mathrm{~g}$ BJ with $400 \mathrm{~g}$ water; $250 \mathrm{~g}$ BJ with $250 \mathrm{~g}$ water and $500 \mathrm{~g}$ BJ (100\% BJ; James White Drinks Limited). The control drink and BJ drinks were all diluted with low-nitrate mineral water (The Buxton Mineral Water Company Limited).

Study 2. A further study was performed in fourteen healthy males to investigate the effects of red or white beetroot-enriched bread products on BP. Subjects were randomly assigned to one of three different intervention bread products (Eccentricities Limited): $200 \mathrm{~g}$ white bread (control, $0 \mathrm{~g}$ beetroot enrichment), or $200 \mathrm{~g}$ bread enriched with either white or red beetroot (comprising $50 \%$ of the total weight of dough before baking). In both studies, ABP was measured automatically every $15 \mathrm{~min}$ from 08.00 hours until 13.00 hours, every $30 \mathrm{~min}$ from 13.00 hours until 22.00 hours, and every $60 \mathrm{~min}$ from 22.00 hours until 08.00 hours. Additionally, urine samples were collected at baseline, 2 and $4 \mathrm{~h}$ after intervention food consumption, and as an overnight collection $(24 \mathrm{~h})$, which was returned the following morning. The sample volumes were recorded, the urine was divided into aliquots and frozen at $-20^{\circ} \mathrm{C}$ for later analysis. During the study days, subjects remained in a semi-recumbent position.

\section{Dietary protocol and intervention meals}

In both studies, subjects consumed a low-nitrate and -nitrite diet $1 \mathrm{~d}$ before each study day. All study subjects were instructed not to take any vitamins or minerals, or other 
dietary supplements for 1 week before and during the intervention period. Standard, low-nitrate meals were provided for the night before the study day, and lunch and dinner on study days (Sainsbury's 'Be Good to Yourself' range; Sainsbury's Limited).

The intervention meals given in study 1 consisted of dose 1 : $0 \mathrm{~g}$ BJ (500 g water) as a control; dose 2: $100 \mathrm{~g}$ BJ with $400 \mathrm{~g}$ water; dose 3: $250 \mathrm{~g}$ BJ with $250 \mathrm{~g}$ water and dose $4: 500 \mathrm{~g}$ BJ (100\% BJ; James White Drinks Limited), corresponding to $<0.05 \mathrm{mmol}$ nitrate, $2.3 \mathrm{mmol}$ nitrate, $5.7 \mathrm{mmol}$ nitrate and $11.4 \mathrm{mmol}$ nitrate for dose 1: $0 \mathrm{~g} \mathrm{BJ}$; dose 2: $100 \mathrm{~g}$ BJ; dose 3: $250 \mathrm{~g}$ BJ and dose 4: $500 \mathrm{~g} \mathrm{BJ}$, respectively. The control drink and BJ drinks were all diluted with low-nitrate mineral water (The Buxton Mineral Water Company Limited). On each study day, subjects received a standardised breakfast ( $50 \mathrm{~g}$ Nestlé Shreddies and $125 \mathrm{ml}$ semi-skimmed milk).

The intervention meals given in study 2 consisted of the following: $200 \mathrm{~g}$ white bread (control, $0 \mathrm{~g}$ beetroot enrichment), or $200 \mathrm{~g}$ bread enriched with either white or red beetroot (comprising $50 \%$ of the total weight of dough before baking). The bread $(200 \mathrm{~g})$ was served as sandwiches with $25 \mathrm{~g}$ Philadelphia cheese spread. The beetroot used in the bread was grown on the same farm under identical conditions and soil (Marsh Produce). In addition, the quantity of beetroot in the bread products was equivalent to $100 \mathrm{~g} \mathrm{BJ}$, administered as the lowest dose from study 1 to have a functional effect in human subjects. The nitrate concentrations of the beetroot-enriched breads $(200 \mathrm{~g})$ were as follows: $<0.05 \mathrm{mmol}$ nitrate, 1.8 and $1.6 \mathrm{mmol}$ nitrate for no-beetroot, red beetroot-enriched bread and white beetroot-enriched bread, respectively. The composition of the intervention meals is shown in Table 1.

Low-nitrate water was provided, which subjects were asked to consume for the same period as the low-nitrate diet (The Buxton Mineral Water Company Limited) and to drink throughout the study day. The intervention foods were given immediately after four baseline BP readings and a baseline urine sample, at approximately 09.00 hours on study days. Participants were asked to finish their intervention foods within $15 \mathrm{~min}$. To ensure compliance to the low-nitrate diet, subjects were asked to fill in a $24 \mathrm{~h}$ dietary recall for $1 \mathrm{~d}$ before the study days and after each study day.

\section{Ambulatory $24 \mathrm{~h}$ blood pressure measurements}

$\mathrm{BP}$ was measured using a non-invasive ABP monitor (ABPM TM-243; A\&D Instruments Limited), which met the British Hypertension Society standards for accuracy and performance. ABP monitors were fitted by one researcher at the start of each study day and subjects were asked to leave the monitors on for a period of $24 \mathrm{~h}$. Subjects rested for at least $15 \mathrm{~min}$ before the BP monitors were fitted. All readings were performed on the left arm on each study day. The cuff was programmed to inflate automatically for a total period of $24 \mathrm{~h}$ post-juice or bread consumption. Once the volunteers left the Nutrition Unit, they were instructed to avoid any strenuous cardiovascular exercise, until the end of the $24 \mathrm{~h}$ period. At each subsequent BP measurement, volunteers were asked

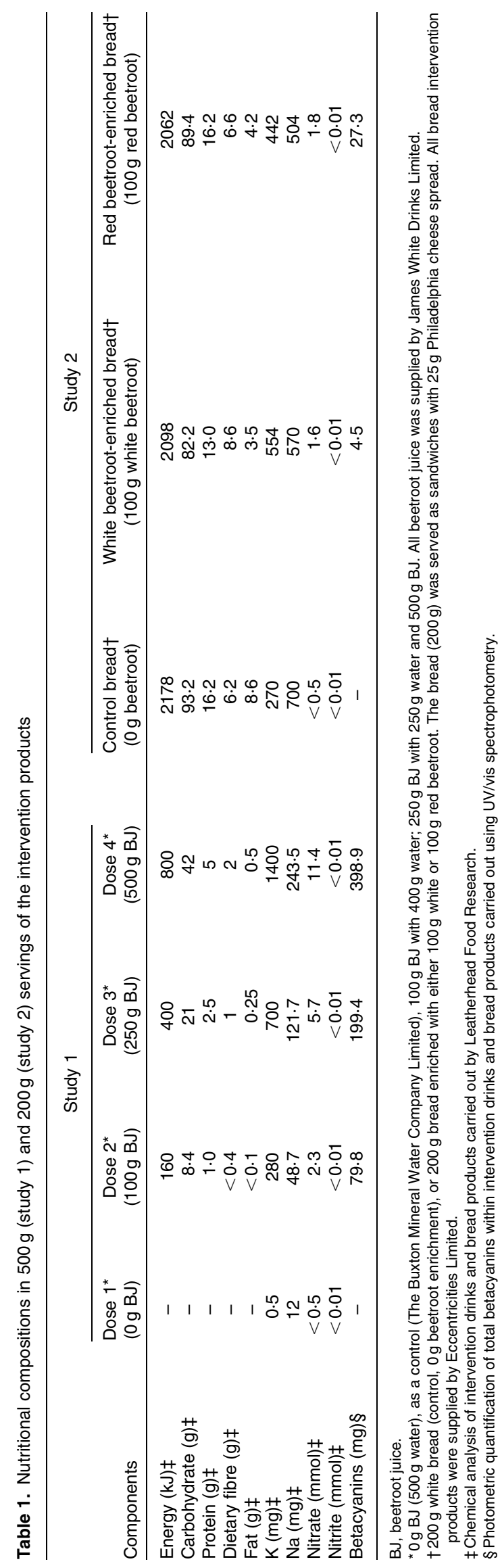


to hang their arm loosely down the side of their body, while keeping still until the end of the measurement. If walking, the volunteers were instructed to stop and remain standing while the measurement was being recorded. Volunteers were provided with a $24 \mathrm{~h}$ BP diary card, which they were required to fill in with information on their daily activities throughout the $24 \mathrm{~h}$ period.

\section{Total urinary nitrate/nitrite measurements}

Nitrate/nitrite $\left(\mathrm{NO}_{x}\right)$ measurements were carried out on urine samples using a NO quantification kit (Active Motif). Creatinine was determined for all urine samples, using the ILAB 600 (Instrumentation Laboratories Limited). Total urinary $\mathrm{NO}_{x}$ determination was used as a surrogate marker of systemic NO production. It should be noted that this measurement is not a reliable index of NO bioactivity in vivo, but may be used as an indicator of $\mathrm{NO}$ production.

\section{Statistical analysis}

All subjects who completed the study were included in the data analysis. Data were analysed using Excel (Microsoft Office; Microsoft Limited) and SPSS 18 for Microsoft Windows (SPSS, Inc.). All data are expressed as means with their standard errors of the mean and checked for normality using the Shapiro-Wilk test, as the number of subjects was less than fifty. Unpaired $t$ tests were used to compare the two study groups at baseline. The AUC was calculated as a summation measure for BP. The period between 0 and $4 \mathrm{~h}$ represents the time the participants spent in the Nutrition Unit under standard resting conditions, 0 and $13 \mathrm{~h}$ represents the total awake period, and 0 and $24 \mathrm{~h}$ includes the total $24 \mathrm{~h}$ period after intervention food ingestion. One-way ANOVA was used for AUC comparisons, and subsequently Bonferroni multiple pairwise comparison post hoc tests to identify the differences between the control (no beetroot) and 100, 250 and $500 \mathrm{~g}$ BJ and beetroot-enriched bread, $200 \mathrm{~g}$ white beetroot $(100 \mathrm{~g})$-enriched bread and $200 \mathrm{~g}$ red beetroot $(100 \mathrm{~g})$-enriched bread. Urine sample data were compared using repeated-measures ANOVA. In all cases, $P \leq 0.05$ was considered as statistically significant unless otherwise stated.

\section{Results}

\section{Subject characteristics}

A total of eighteen men completed study 1 and fourteen men completed study 2 . There were no adverse events reported in response to intervention products, apart from beeturia (red urine), which is a common side effect of beetroot consumption. Table 2 shows the mean and range of baseline characteristics of the subjects. There were no significant differences in the general characteristics of the individuals recruited for the two separate studies.
Table 2. Baseline characteristics of the subjects before ingestion of intervention juice (study 1) or bread products (study 2)

(Mean values with their standard errors, $n 18$ (study 1), $n 14$ (study 2))

\begin{tabular}{|c|c|c|c|c|}
\hline \multirow[b]{3}{*}{ Characteristics } & \multicolumn{4}{|c|}{ Subjects } \\
\hline & \multicolumn{2}{|c|}{ Study $1^{*}$} & \multicolumn{2}{|c|}{ Study $2^{*}$} \\
\hline & Mean & SEM & Mean & SEM \\
\hline Age (years) & 31.4 & $3 \cdot 0$ & $25 \cdot 1$ & 0.8 \\
\hline BMI (kg/m²) & 24.4 & 0.9 & 23.5 & 0.7 \\
\hline $\mathrm{SBP}(\mathrm{mmHg})$ & $130 \cdot 6$ & 3.2 & 131.2 & $5 \cdot 2$ \\
\hline $\mathrm{DBP}(\mathrm{mmHg})$ & 82.1 & $5 \cdot 6$ & 78.2 & 4.0 \\
\hline
\end{tabular}

SBP, systolic blood pressure; DBP, diastolic blood pressure.

* There were no significant differences in baseline characteristics between the participants in study 1 and study 2 (unpaired $t$ test): $P=0.05$.

\section{$24 \mathrm{~h}$ ambulatory blood pressure}

There were no significant differences in systolic BP (SBP) and DBP between the two groups during the hour before consumption of BJ, beetroot-enriched bread or controls (Table 2).

Study 1 (beetroot juice dose-response study). Postprandial SBP and DBP after the ingestion of $0 \mathrm{~g} \mathrm{BJ}$ (control), 100, 250 and $500 \mathrm{~g}$ BJ are shown in Fig. 1. SBP and DBP began to decrease $90 \mathrm{~min}$ after the ingestion of all $\mathrm{BJ}$ intervention drinks (100, 250 and $500 \mathrm{~g}$ BJ), in accordance with the increasing dose of $\mathrm{BJ}$. The peak reduction in SBP and DBP occurred at $2-3 \mathrm{~h}$ in the order of $13 \cdot 1,20 \cdot 5$ and $22 \cdot 2 \mathrm{mmHg}$ and 16.6, 14.6 and 18.3 for 100, 250 and $500 \mathrm{~g} \mathrm{BJ}$, respectively, compared with the water control $(0 \mathrm{~g}$ BJ $)$. There was a significant effect of treatment on the AUC for both SBP from 0 to $4 \mathrm{~h}$ (Fig. 1(a), $P=0.008$ ), 0 to $13 \mathrm{~h}$ (Fig. 1(c), $P=0.001$ ) and 0 to $24 \mathrm{~h}$ (Fig. 1(e), $P=0.006$ ) and DBP from 0 to $4 \mathrm{~h}$ (Fig. 1(b), $P=0.001$ ), 0 to $13 \mathrm{~h}$ (Fig. $1(\mathrm{~d}), P=0.001$ ) and 0 to $24 \mathrm{~h}$ (Fig. 1(f), $P=0.001$ ) after the consumption of 100, 250 and $500 \mathrm{~g}$ BJ, respectively. The Bonferroni post hoc test revealed that after ingestion of $100,250,500 \mathrm{~g}$ BJ, SBP was significantly lower from 0 to $4 \mathrm{~h}$ (Fig. 1(a), $250 \mathrm{~g}$ BJ, $P=0 \cdot 04 ; 500 \mathrm{~g}$ BJ, $P=0.008$ ), 0 to $13 \mathrm{~h}$ (Fig. 1 (c), $250 \mathrm{~g} \mathrm{BJ}, P=0 \cdot 02 ; 500 \mathrm{~g} \mathrm{BJ}$, $P=0.001$ ) and for the remaining $24 \mathrm{~h}$ period (Fig. 1(e), $500 \mathrm{~g}$ $\mathrm{BJ}, P=0.004)$ compared with the control drink (water). DBP was significantly lower from 0 to $4 \mathrm{~h}$ after ingestion of $100 \mathrm{~g}$ BJ (Fig. 1(b), $P=0.002$ ) and $500 \mathrm{~g} \mathrm{BJ}$ (Fig. 1(b), $P=0.001), 0$ to $13 \mathrm{~h}$ (Fig. $1(\mathrm{~d}), 100 \mathrm{~g} \mathrm{BJ}, P=0.003 ; 250 \mathrm{~g} \mathrm{BJ}, P=0.03 ; 500 \mathrm{~g}$ $\mathrm{BJ}, P=0.001$ ) and for the remaining $24 \mathrm{~h}$ period (Fig. 1(f), $100 \mathrm{~g} \mathrm{BJ}, P=0.001 ; 250 \mathrm{~g} \mathrm{BJ}, P=0.02 ; 500 \mathrm{~g} \mathrm{BJ}, P=0.001) \mathrm{com}-$ pared with the control drink (water). In addition, mean heart rate did not change significantly over the $24 \mathrm{~h}$ period postingestion of water control, 100, 250 or $500 \mathrm{~g}$ BJ (69.9 (SEM 1.2), 69.2 (SEM 1.2), $70 \cdot 9$ (SEM 1.8) and 71.3 (SEM 1.3), respectively). There appeared to be a near dose-dependent effect from 0 to $24 \mathrm{~h}$, as shown by the pattern of decreasing AUC for increasing BJ dose (Fig. 1(e) and (f)).

Study 2 (beetroot-enriched bread study). Postprandial SBP and DBP after the consumption of three different intervention breads enriched with no beetroot (control), $100 \mathrm{~g}$ white beetroot or $100 \mathrm{~g}$ red beetroot are shown in Fig. 2. BP started decreasing approximately $60 \mathrm{~min}$ after the ingestion 
(a)

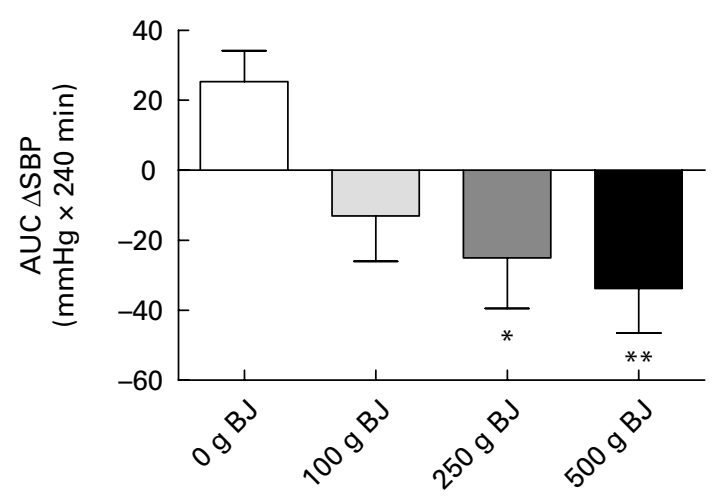

(c)

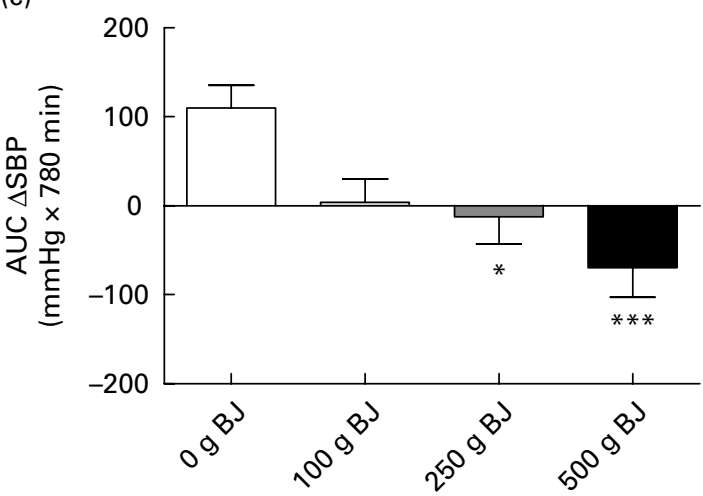

(e)

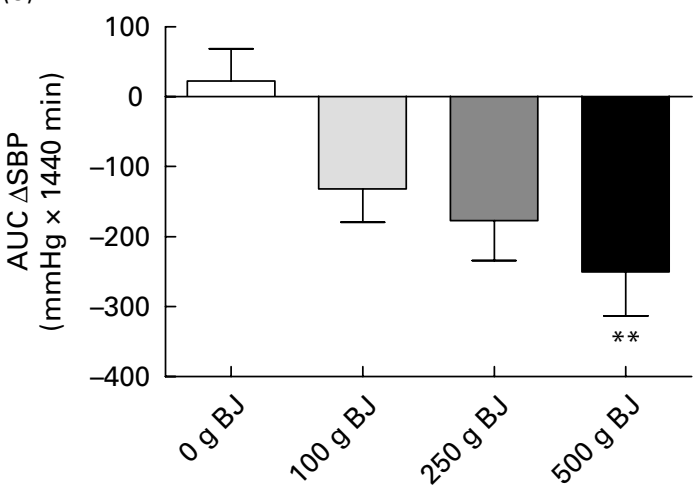

(b)

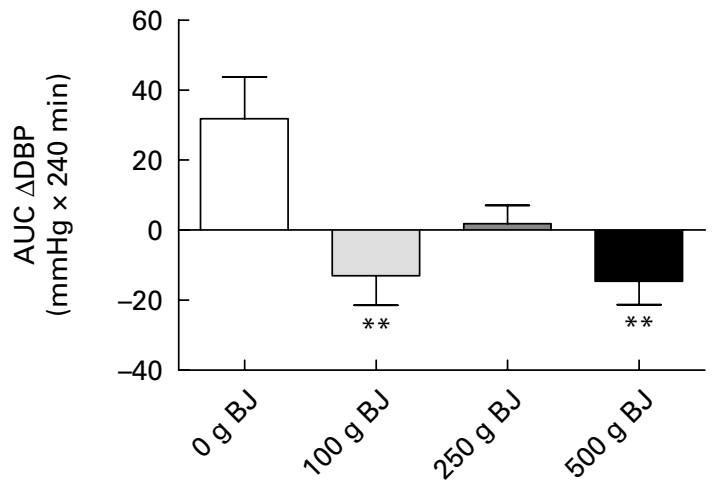

(d)

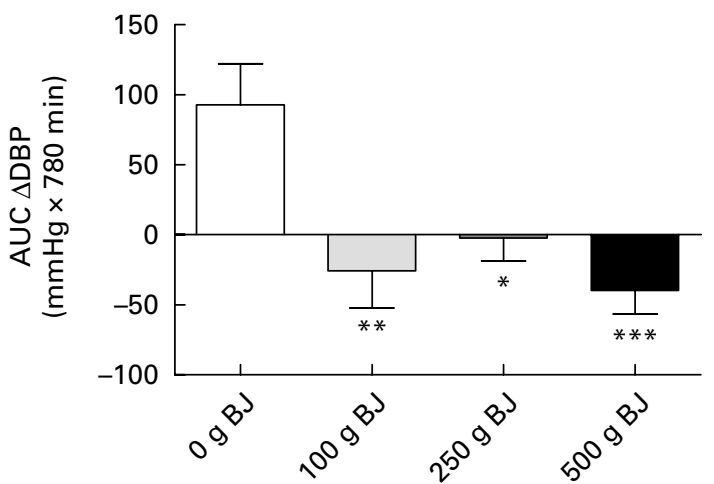

(f)

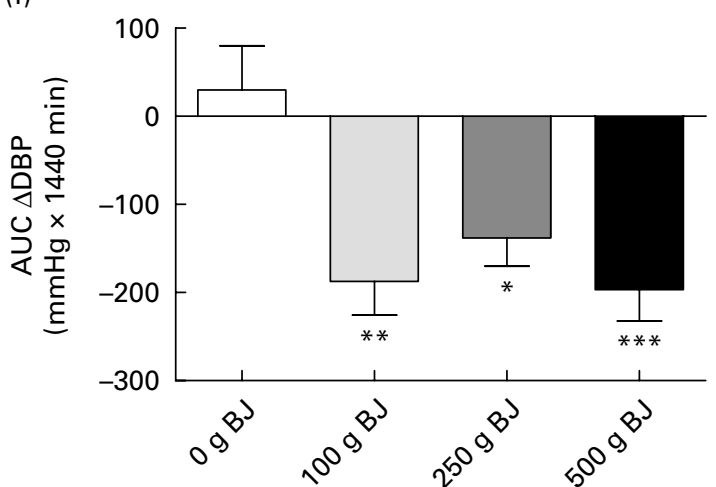

Fig. 1. Study 1: mean change in area under the postprandial systolic blood pressure (SBP) curve from (a) 0 to $4 \mathrm{~h}$, (c) 0 to $13 \mathrm{~h}$ and (e) 0 to $24 \mathrm{~h}$ and diastolic blood pressure (DBP) from (b) 0 to $4 \mathrm{~h}$, (d) 0 to $13 \mathrm{~h}$ and (f) 0 to $24 \mathrm{~h}$ following consumption of dose 1 (control, water, $0 \mathrm{~g}$ beetroot juice (BJ)), dose 2 (100 g BJ with $400 \mathrm{~g}$ water), dose $3(250 \mathrm{~g} \mathrm{BJ}$ with $250 \mathrm{~g}$ water) and dose $4(500 \mathrm{~g} \mathrm{BJ}$ ). All intervention drinks were made up to $500 \mathrm{~g}$ with low-nitrate water (The Buxton Mineral Water Company Limited). Values are means, with standard errors of the mean represented by vertical bars. Mean values were significantly different from the control drink (water): ${ }^{\star} P<0.05,{ }^{\star *} P<0.01,{ }^{* \star *} P<0.001$; Bonferroni post hoc test.

of beetroot-enriched breads compared with the bread control (no beetroot). Peak differences in SBP and DBP occurred between 2 and $3 \mathrm{~h}$ in the order of 19.3 and $23.6 \mathrm{mmHg}$ and 16.5 and $23.2 \mathrm{mmHg}$ for white and red beetroot-enriched breads, respectively, compared with the control bread ( $0 \mathrm{~g}$ beetroot). The AUC for SBP from 0 to $4 \mathrm{~h}$ following beetroot-enriched bread consumption was lower for both beetroot-enriched breads compared with the control bread (Fig. 2(a)), which continued from 0 to $13 \mathrm{~h}$ (Fig. 2(c)) and for the remaining $24 \mathrm{~h}$ period (Fig. 2(e)), but did not reach significance. However, there was a significant effect of treatment on the AUC for DBP from 0 to $4 \mathrm{~h}$ (Fig. 2(b), $P=0.03$ ), 0 to $13 \mathrm{~h}$ (Fig. $2(\mathrm{~d}), P=0.04$ ) and from 0 to $24 \mathrm{~h}$ (Fig. 2(f), $P=0.03$ ). Following ingestion of bread enriched with $100 \mathrm{~g}$ red beetroot, DBP was significantly lower from 0 to $4 \mathrm{~h}(P=0.05), 0$ to $13 \mathrm{~h}(P=0.04)$ and 0 to $24 \mathrm{~h}(P=0.03)$, compared with the control bread (no beetroot). Following ingestion of $200 \mathrm{~g}$ bread enriched with $100 \mathrm{~g}$ white beetroot, DBP was lower compared with the control ( $0 \mathrm{~g}$ beetroot) but did not reach significance. SBP was lower for both beetroot-enriched bread interventions at all time points compared with the control bread ( $0 \mathrm{~g}$ beetroot), but failed to reach 

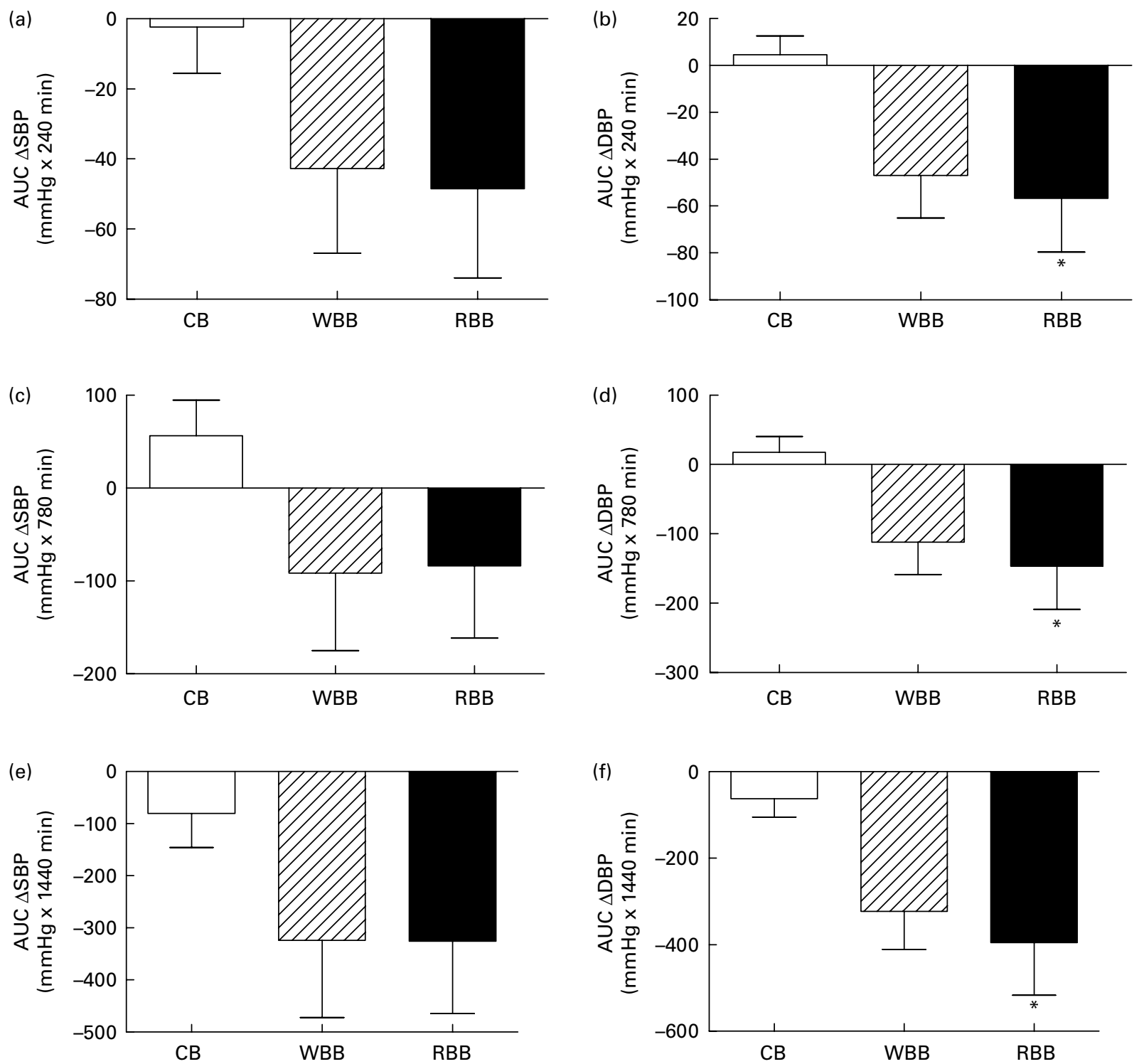

Fig. 2. Study 2: mean change in area under the postprandial systolic blood pressure (SBP) curve from (a) 0 to $4 \mathrm{~h}$, (c) 0 to $13 \mathrm{~h}$ and (e) 0 to $24 \mathrm{~h}$ and diastolic blood pressure (DBP) from (b) 0 to $4 \mathrm{~h}$, (d) 0 to $13 \mathrm{~h}$ and (f) 0 to $24 \mathrm{~h}$ following consumption of $200 \mathrm{~g}$ control bread (CB) ( $0 \mathrm{~g}$ beetroot), 200 $\mathrm{g}$ white beetroot (WBB) and red beetroot (RBB) enriched bread (100 g red or white beetroot). Values are means, with standard errors of the mean represented by vertical bars. ${ }^{*}$ Mean values were significantly different from the control bread ( $0 \mathrm{~g}$ beetroot) $(P<0.05$; Bonferroni post hoc test)

statistical significance. There were no statistical differences between the red and white beetroot-enriched breads for both DBP and SBP over the $24 \mathrm{~h}$ period after ingestion of the intervention breads. In addition, mean heart rate did not change significantly over the $24 \mathrm{~h}$ period after consumption of the control bread ( $0 \mathrm{~g}$ beetroot), red or white beetroot-enriched breads (73.6 (SEM 1.2), 74.9 (SEM 1.2) and 74.2 (SEM 1·1)).

\section{Total urinary nitrate/nitrite}

Study 1 (beetroot juice dose-response study). Total urinary $\mathrm{NO}_{x}$ were significantly higher for the 100 and $250 \mathrm{~g}$ BJ doses from 0 to $4 \mathrm{~h}$ post-consumption compared with the $0 \mathrm{~g} \mathrm{BJ}$ control (100 g BJ, $P<0 \cdot 01 ; 250$ g BJ, $P<0 \cdot 001$; Fig. 3(a)). Total urinary $\mathrm{NO}_{x}$ increased significantly from 0 to $4 \mathrm{~h}$ post-consumption of $500 \mathrm{~g}$ BJ and remained significantly higher at $24 \mathrm{~h}$ compared with the $0 \mathrm{~g}$ BJ control $(P<0 \cdot 001$; Fig. 3(a)).

Study 2 (beetroot-enriched bread study). Following consumption of the beetroot-enriched breads, total urinary $\mathrm{NO}_{x}$ increased from 0 to $4 \mathrm{~h}$, but only reached significance for the red beetroot-enriched bread $(P<0 \cdot 05$; Fig. 3(b)).

\section{Discussion}

One of the largest public health schemes in the Western world in the past decade has been to increase fruit and vegetable consumption. However, despite this, recent data from the National Diet and Nutrition Survey highlight that the average British adult consumes less than four portions of fruit and 

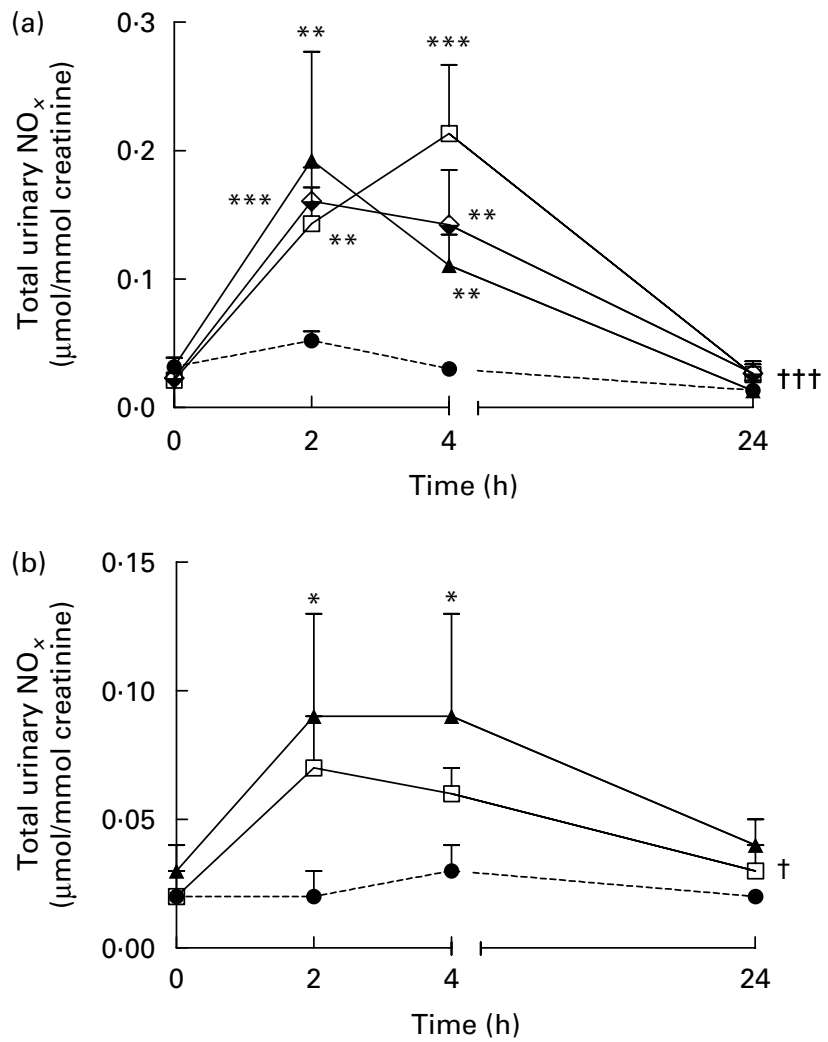

Fig. 3. Mean total urinary nitrate/nitrite $\left(\mathrm{NO}_{x}\right)$ concentrations for (a) dose 1 (control, water, $0 \mathrm{~g}$ beetroot juice $(\mathrm{BJ} ;---\bullet--))$, dose $2(100 \mathrm{~g} \mathrm{BJ}$ with $400 \mathrm{~g}$ water; $\neg-)$ ), dose 3 ( $250 \mathrm{~g} \mathrm{BJ}$ with $250 \mathrm{~g}$ water; $\triangleleft)$ ) and dose $4(500 \mathrm{~g}$ $\mathrm{BJ} ;-\square$ ) and (b) $200 \mathrm{~g}$ control bread (0 $\mathrm{g}$ beetroot; -.----), $200 \mathrm{~g}$ bread enriched with either $100 \mathrm{~g}$ white beetroot $(\square-$ ) or $100 \mathrm{~g}$ red beetroot $(\neg)$ at baseline $(0 \mathrm{~h})$ and 2,4 and $24 \mathrm{~h}$ consumption of intervention juices or breads. Values are means, with standard errors of the mean represented by vertical bars. Mean values were significantly different between the groups, i.e. control juice (water), bread with BJ or beetroot-enriched bread: ${ }^{*} P<0.05, \quad{ }^{* *} P<0.01,{ }^{* * *} P<0.001 \quad$ (Bonferroni post hoc test); $\dagger P<0.05$, $\dagger+\dagger P<0.001$ (repeated-measures ANOVA).

vegetables a day. Interestingly, $64 \mathrm{~g}$ of white bread are consumed by almost $80 \%$ of British adults daily ${ }^{(24)}$. Taken together, these data suggest that enriching bread with fruit or vegetables may be a novel and useful strategy to increase the consumption of fruit and vegetables.

The protective effects of diets rich in fruit and vegetables have previously been attributed to several antioxidant vitamins. However, large-scale trials have failed to ascertain these beneficial effects. Recently, it has been postulated that the cardioprotective effects seen from consumption of green leafy vegetables and beetroot may be due to their high dietary nitrate content ${ }^{(16,25)}$. Dietary nitrate generates NO independently of the conventional endogenous NO synthase pathway, by reduction to nitrite and subsequently to $\mathrm{NO}$ in vivo ${ }^{(25)}$. Since hypertension is associated with a diminished endogenous NO production, the development of novel cost-effective strategies to incorporate dietary nitrate and therefore additional NO into the diet is of considerable interest.

Herein, we demonstrated that consumption of 100, 250 and $500 \mathrm{~g}$ BJ reduced SBP and DBP over a period of $24 \mathrm{~h}$ when compared with the control drink ( $0 \mathrm{~g}$ beetroot). There was a clear trend for $\mathrm{BP}$ reduction with increasing $\mathrm{BJ}$ dose, with a dose as low as $100 \mathrm{~g}$ resulting in a significant BP-lowering effect. A novel finding from these studies was that both SBP and DBP were substantially lower following consumption of bread enriched with either $100 \mathrm{~g}$ white or red beetroot, compared with the control bread ( $0 \mathrm{~g}$ beetroot). Although this only reached significance for red beetroot-enriched bread, it suggests that processing had minimal impact on the physiological effects of beetroot on BP. Therefore, enriching bread with fruit and vegetables may prove to be a good vehicle for increasing the intake of fruit and vegetables with minimal impact on habitual diet. Previous studies have found a peak decrease in SBP of 5.4 (SEM 1.5) and 10.4 (SEM 3.0) mmHg 2 to $3 \mathrm{~h}$ following consumption of $250 \mathrm{ml}(5.5 \mathrm{mmol} \text { nitrate })^{(20)}$ and $500 \mathrm{ml}(22.5 \mathrm{mmol} \text { nitrate })^{(16)} \mathrm{BJ}$. In the present studies, the peak SBP reductions were of greater magnitude. This may be due to differences in baseline BP of the subjects in the studies. Kapil et $a l .{ }^{(20)}$ found that the magnitude of BP response was directly related to baseline BP. Thus, a higher baseline BP would result in a greater magnitude of BP reduction.

Total urinary $\mathrm{NO}_{x}$ concentrations were measured as an indicator of systemic NO production and increased in accordance with reductions in BP after consumption of $\mathrm{BJ}$ and beetroot-enriched breads. These results are in accordance with previous findings which suggest that urinary nitrate reaches peak concentrations $4-6 \mathrm{~h}$ and returns to baseline $24 \mathrm{~h}$ after supplementation with nitrate ${ }^{(26,27)}$ and dietary nitrate $^{(28)}$. The metabolic fate of $\mathrm{NO}$ includes oxidation to nitrate by oxyhaemoglobin in erythrocytes and autoxidation to nitrite. Nitrate and nitrite circulate in the blood and are ultimately excreted in the urine. Total urinary $\mathrm{NO}_{x}$ determination may be used as an index of systemic NO production, but is not necessarily an indicator of endothelial NO synthase activity in vivo.

Interestingly, white beetroot, a betacyanin-deficient variety, lowered BP to a similar extent as red beetroot, a betalainabundant variety, compared with the control ( $0 \mathrm{~g}$ beetroot). This observation suggests that components other than betalain compounds are likely to be responsible for the BP-lowering effects observed. Although beetroot contains other potentially bioactive compounds such as vitamin $\mathrm{C}$, folate, $\mathrm{K}$, dietary fibre and polyphenols, we suggest that it is the dietary nitrate that is partly responsible for the beneficial effects observed from beetroot consumption by bioconversion to nitrite and then to NO in vivo. In humans, $20-25 \%$ of ingested nitrate is secreted in saliva and approximately $20 \%$ of this is converted to nitrite by commensal Gram-negative bacteria on the dorsal surface of the tongue, resulting in nitrite-rich saliva ${ }^{(29)}$. The salivary nitrite is absorbed in the stomach and enters the circulation where NO synthesis occurs by the reduction of nitrite within the blood vessel wall ${ }^{(17)}$ and erythrocytes ${ }^{(18)}$. It is possible that the nitrite derived from ingested nitrate, in the present studies, provided an intravascular source of NO that resulted in vasodilation within the microcirculation to produce a decrease in peripheral resistance and therefore a reduction in BP. 
The hypothesis that it was the dietary nitrate present in the BJ and beetroot-enriched breads that caused the beneficial effects on BP was supported by a study showing that supplementation of healthy volunteers with sodium nitrate $(0.1 \mathrm{mmol} / \mathrm{kg}$ per $\mathrm{d})$ over $3 \mathrm{~d}$ reduced DBP by $3.7 \mathrm{mmHg}$, compared with $\mathrm{NaCl}$ control ${ }^{(15)}$. Moreover, the magnitude of $\mathrm{BP}$ reduction and plasma nitrite concentration was diminished when the enterosalivary circulation was interrupted by spitting out all saliva following consumption of $500 \mathrm{ml} \mathrm{BJ}^{(16)}$.

In the present studies, subjects were in a controlled environment, sitting or in a semi-recumbent position, for the first $4 \mathrm{~h}$ after intervention drink and bread consumption. However, the AUC for SBP remained lower following consumption of both beetroot-enriched breads for up to $13 \mathrm{~h}$ post-consumption, compared with the no-beetroot condition. This is noteworthy, as it indicates that the BP-lowering effect was sustained throughout the afternoon period, although understandably less marked than the initial effect due to the confounding effect of daily activities. This prolonged effect is suggestive of the impact of colonic metabolic products causing further release of NO into the circulation. It has been previously reported that anaerobic gut flora can reduce nitrate to nitrite $^{(30)}$. It is therefore possible that nitrite is further converted to bioactive $\mathrm{NO}$ in the colon, which after absorption exerts vasodilatory effects, therefore prolonging the effects of $\mathrm{BJ}$ and bread on BP.

A limitation of these pilot studies is the lack of postprandial blood samples. As a result, it is currently unknown how the plasma nitrate and nitrite are affected by BJ or beetrootenriched bread ingestion and whether they occur in association with changes in BP. Although determination of urinary $\mathrm{NO}_{x}$ concentrations is suggestive of an association between BP-lowering effects of $\mathrm{BJ}$ and breads and nitrate consumption. Another possible limitation is the relatively small number of subjects who took part in these studies. However, even with the limited number of participants, both studies were suitably powered to detect significant BP changes. A larger postprandial test meal study is being performed to verify these findings and to investigate other parameters of vascular function such as micro-vessel endothelial function.

In conclusion, results from these studies are the first to demonstrate that acute ingestion of $\mathrm{BJ}$ lowered $\mathrm{BP}$ in a near dose-dependent manner in healthy normotensive individuals. In addition, novel bread enriched with either white or red beetroot, equivalent to $100 \mathrm{~g} \mathrm{BJ}$, resulted in similar BP reductions. This may suggest that nitrate in the beetroot is a major contributor to the BP reduction observed, whereas betalains had minimal impact, and that processing beetroot during bread production did not have a significant impact on the BP-lowering effects. Therefore, enriching bread with beetroot may provide a useful vehicle for the delivery of dietary nitrate and increasing vegetable consumption, with minimal impact on dietary habits.

\section{Acknowledgements}

This study was supported by grants from the University of Reading Research Endowment Trust Fund (RETF) and
Eccentricities Limited. We thank Jan Luff and Cecilia Shen for technical assistance and James White Drinks Limited and Eccentricities Limited for supplying the juice and breads. The authors' responsibilities were as follows: D. A. H., J. A. L., T. W. G. and L. M. designed the studies; D. A. H. and N. K. conducted the research; D. A. H. analysed the data; D. A. H., J. A. L. and T. W. G. wrote the paper. J. A. L. had primary responsibility for the final content. All authors read and approved the final manuscript. As regards conflicts of interest, T. W. G. is the managing director of Eccentricities Limited. There are no other conflicts of interest.

\section{References}

1. Lawes CMM, Hoorn SV \& Rodgers A (2008) Global burden of blood-pressure-related disease, 2001. Lancet 371, 1513-1518.

2. Lewington S, Clarke R, Qizilbash N, et al. (2002) Age-specific relevance of usual blood pressure to vascular mortality: a meta-analysis of individual data for one million adults in 61 prospective studies. Lancet 360, 1903-1913.

3. MacMahon S, Peto R, Collins R, et al. (1990) Blood pressure, stroke, and coronary heart disease: part 1, prolonged differences in blood pressure: prospective observational studies corrected for the regression dilution bias. Lancet $\mathbf{3 3 5}$, $765-774$

4. Vasan RS, Larson MG, Leip EP, et al. (2001) Impact of highnormal blood pressure on the risk of cardiovascular disease. $N$ Engl J Med 345, 1291-1297.

5. Wang W, Lee ET, Fabsitz RR, et al. (2006) A longitudinal study of hypertension risk factors and their relation to cardiovascular disease: the strong heart study. Hypertension $\mathbf{4 7}$, 403-409.

6. Collins R, Peto R, MacMahon S, et al. (1990) Blood pressure, stroke, and coronary heart disease: part 2, short-term reductions in blood pressure: overview of randomised drug trials in their epidemiological context. Lancet 335 , $827-838$.

7. Julius S, Nesbitt SD, Egan BM, et al. (2006) Feasibility of treating prehypertension with an angiotensin-receptor blocker. N Engl J Med 354, 1685-1697.

8. Appel LJ, Moore TJ, Obarzanek E, et al. (1997) A clinical trial of the effects of dietary patterns on blood pressure. $N$ Engl J Med 336, 1117-1124.

9. Zhang X, Shu X-O, Xiang Y-B, et al. (2011) Cruciferous vegetable consumption is associated with a reduced risk of total and cardiovascular disease mortality. Am J Clin Nutr 94, $240-246$

10. Vivekananthan DP, Penn MS, Sapp SK, et al. (2003) Use of antioxidant vitamins for the prevention of cardiovascular disease: meta-analysis of randomised trials. Lancet $\mathbf{3 6 1}$, 2017-2023.

11. Habauzit V \& Morand C (2011) Evidence for a protective effect of polyphenols-containing foods on cardiovascular health: an update for clinicians. Ther Adv Chonic Dis (epublication ahead of print 5 December 2011).

12. Joshipura KJ, Ascherio A, Manson JE, et al. (1999) Fruit and vegetable intake in relation to risk of ischemic stroke. JAMA 282, 1233-1239.

13. Joshipura KJ, Hu FB, Manson JE, et al. (2001) The effect of fruit and vegetable intake on risk for coronary heart disease. Ann Intern Med 134, 1106-1114.

14. Cannon RO III (1998) Role of nitric oxide in cardiovascular disease: focus on the endothelium. Clin Chem 44, 1809-1819. 
15. Larsen FJ, Ekblom B, Sahlin K, et al. (2006) Effects of dietary nitrate on blood pressure in healthy volunteers. $N$ Engl J Med 355, 2792-2793.

16. Webb AJ, Patel N, Loukogeorgakis S, et al. (2008) Acute blood pressure lowering, vasoprotective, and antiplatelet properties of dietary nitrate via bioconversion to nitrite. Hypertension 51, 784-790.

17. Li H, Cui H, Kundu TK, et al. (2008) Nitric oxide production from nitrite occurs primarily in tissues not in the blood. J Biol Chem 283, 17855-17863.

18. Webb AJ, Milsom AB, Rathod KS, et al. (2008) Mechanisms underlying erythrocyte and endothelial nitrite reduction to nitric oxide in hypoxia: role for xanthine oxidoreductase and endothelial nitric oxide synthase. Circ Res 103, 957-964.

19. Lundberg JO, Weitzberg E \& Gladwin MT (2008) The nitratenitrite-nitric oxide pathway in physiology and therapeutics. Nat Rev Drug Discov 7, 156-167.

20. Kapil V, Milsom AB, Okorie M, et al. (2010) Inorganic nitrate supplementation lowers blood pressure in humans: role for nitrite-derived NO. Hypertension 56, 274-281.

21. Halvorsen BL, Holte K, Myhrstad MCW, et al. (2002) A systematic screening of total antioxidants in dietary plants. J Nutr 132, 461-471.

22. Wettasinghe M, Bolling B, Plhak L, et al. (2002) Phase II enzyme-inducing and antioxidant activities of beetroot
(Beta vulgaris L.) extracts from phenotypes of different pigmentation. J Agric Food Chem 50, 6704-6709.

23. Kanner J, Harel S \& Granit R (2001) Betalains a new class of dietary cationized antioxidants. J Agric Food Chem 49, 5178-5185.

24. Bates B, Lennox A \& Swan G (2010) NDNS Headline results from Year 1 of the Rolling Programme (2008/2009). http:// www.food.gov.uk/multimedia/pdfs/publication/ndnsreport 0809.pdf

25. Lundberg JO \& Weitzberg E (2005) NO generation from nitrite and its role in vascular control. Arterioscler Thromb Vasc Biol 25, 915-922.

26. Bartholomew B \& Hill MJ (1984) The pharmacology of dietary nitrate and the origin of urinary nitrate. Food Chem Toxicol 22, 789-795.

27. Cortas NK \& Wakid NW (1991) Pharmacokinetic aspects of inorganic nitrate ingestion in man. Pharmacol Toxicol 68 , 192-195.

28. Pannala AS, Mani AR, Spencer JPE, et al. (2003) The effect of dietary nitrate on salivary, plasma, and urinary nitrate metabolism in humans. Free Radic Bio Med 34, 576-584.

29. Lundberg JO, Weitzberg E, Lundberg JM, et al. (1994) Intragastric nitric oxide production in humans: measurements in expelled air. Gut 35, 1543-1546.

30. Sobko T, Reinders CI, Jansson EA, et al. (2005) Gastrointestinal bacteria generate nitric oxide from nitrate and nitrite. Nitric Oxide 13, 272-278. 